\title{
Au-decorated ZnO Nanowires for Selective Ethanol Sensing
}

\author{
S. Singkammo $^{1}$, C. Liewhiran ${ }^{1, *}$, A. Wisitsoraat $^{2}$, S. Phanichphant ${ }^{3}$, D. Zappa ${ }^{4}$, A. Ponzoni ${ }^{4,5}$ \\ G. Sberveglieri ${ }^{4}$, E. Comini, * \\ ${ }^{1}$ Department of Physics and Materials Science, Faculty of Science, Chiang Mai University, Chiang \\ Mai 50202, Thailand \\ ${ }^{2}$ Carbon-based Devices and Nanoelectronics Laboratory, National Electronics and Computer \\ Technology Center, National Science and Technology Development Agency, \\ Klong Luang, Pathumthani 12120, Thailand \\ ${ }^{3}$ Materials Science Research Center, Faculty of Science, Chiang Mai University, Chiang Mai 50202, \\ Thailand \\ ${ }^{4}$ SENSOR Laboratory, University of Brescia, Via D. Valotti 9, 25133 Brescia, \\ Italy $\quad{ }^{5}$ National Institute of Optics (INO), National Research Council of Italy (CNR), \\ Via Branze 45, 25123 Brescia, Italy \\ Corresponding author's e-mail address: \\ cliewhiran@gmail.com (C. Liewhiran), elisabetta.comini@unibs.it (E. Comini)
}

\begin{abstract}
Metal oxide semiconductors based on 1-D nanostructures such as nanorod, nanobelt and nanowire are promising candidates for gas sensing application due to high surface area to volume ratio [1]. ZnO is one of most promising metal oxides, it has a wide band gap (3.37 eV) and applies for gas sensing application [2]. In this work, $\mathrm{ZnO}$ nanowires were grown with vapor-liquid-solid (VLS) mechanism via thermal evaporation-condensation method using $A u$ catalyst for structural evolution [1, 3, 4]. Particularly, the as-prepared $\mathrm{ZnO}$ sensing films were functionalized with Au catalyst by varying the sputtering time ranging from $0-15 \mathrm{~s}$. The choice of Au catalyst comes from its important role in significant enhancement the gas-sensing properties. For the sensing results, all sensors were systematically studied towards $\mathrm{NO}_{2}, \mathrm{NH}_{3}, \mathrm{C}_{3} \mathrm{H}_{6} \mathrm{O}$ and $\mathrm{CO}, \mathrm{C}_{2} \mathrm{H}_{5} \mathrm{OH}$ with different working temperature ranging from 250 to $400^{\circ} \mathrm{C}$ in dry and wet air. Nanowires functionalized with Au sputtering time at $5 \mathrm{~s}$ led to the highest response of 80.7 toward $70 \mathrm{ppm} \mathrm{C}_{2} \mathrm{H}_{5} \mathrm{OH}$, which was higher than that of bare $\mathrm{ZnO}$ nanowire sensor $(S=2.16)$ and those of the other gases at the optimal working temperature of $350^{\circ} \mathrm{C}$ with $30 \%$ humidity. Therefore, the sensor is a promising candidate as a sensitive and selective ethanol detector corresponding to threshold limit value and practical humidity effect for ethanol-sensing applications.
\end{abstract}

Keywords: Zinc oxide, Nanowire, Gold, $\mathrm{C}_{2} \mathrm{H}_{5} \mathrm{OH}$, Gas sensor. 


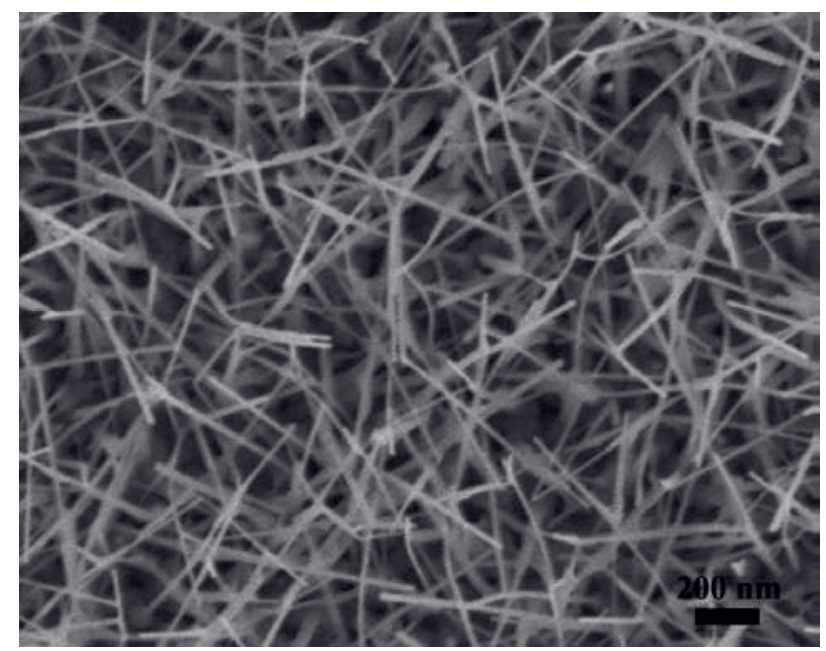

Fig.1. The typical SEM micrographs of as-prepared ZnO nanowires synthesized by vapor-liquid-solid (VLS) mechanism via thermal evaporation-condensation method using Au catalyst for structural evolution.

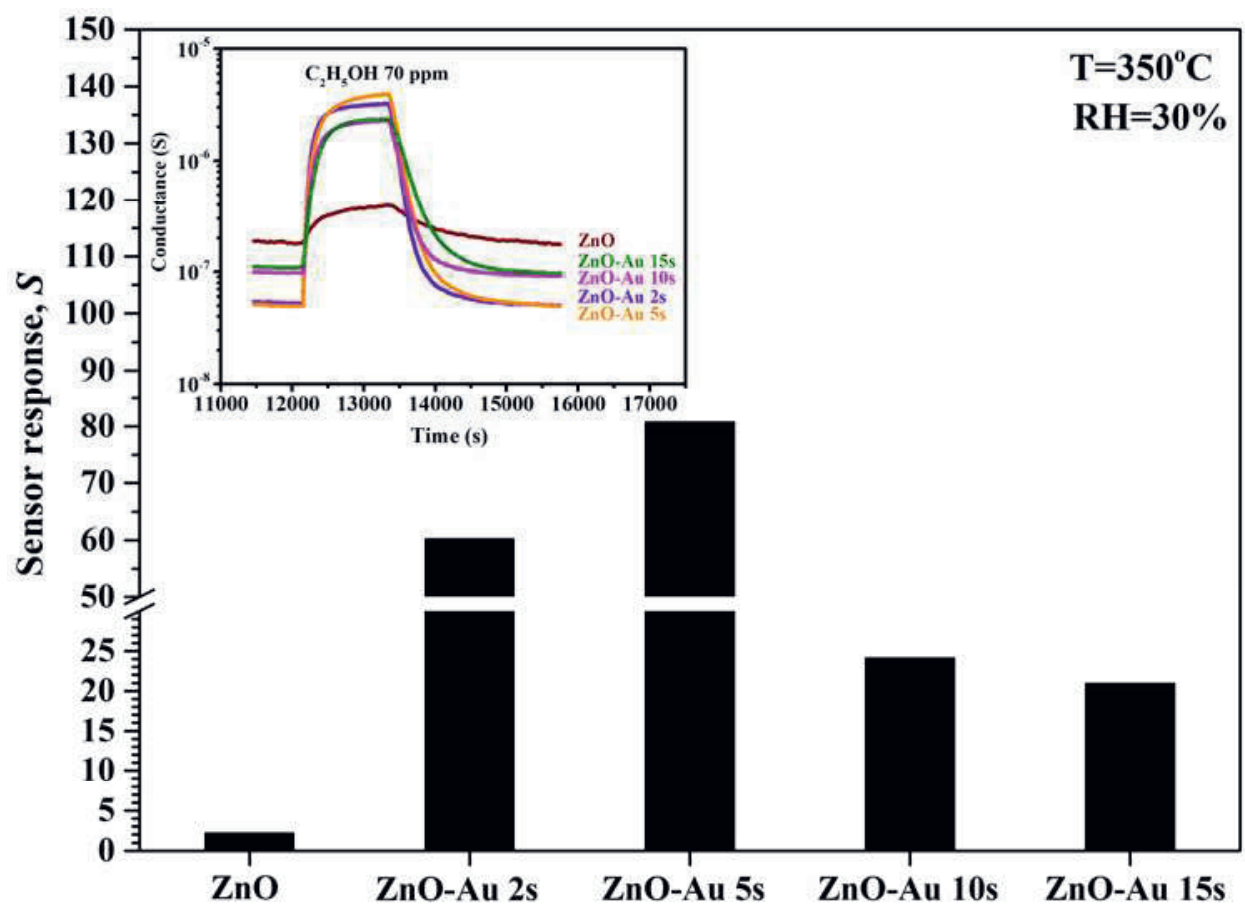

Fig.2. Gas-sensing properties of $\mathrm{ZnO}$ and Au-sputtered $\mathrm{ZnO}$ with sputtering times ranging from 2 to $15 \mathrm{~s}$ under exposure $70 \mathrm{ppm} \mathrm{C}_{2} \mathrm{H}_{5} \mathrm{OH}$ at optimal operating temperature of $350^{\circ} \mathrm{C}$ in relative humidity of $30 \%$. The corresponding changes in conductance are shown in the insets.

\section{References}

[1] E. Comini , C. Baratto , I. Concina , G. Faglia , M. Falasconi, M. Ferroni, V. Galstyan, E. Gobbi, A. Ponzoni, A. Vomiero, D. Zappa, V. Sberveglieri, G. Sberveglieri, Metal oxide nanoscience and nanotechnology for chemical sensors, Sensors and Actuators B 179, 3- 20 (2013); doi: 10.1016/j.snb.2012.10.027.

[2] D. Barreca, D. Bekermann, E. Comini, A. Devi, Roland A. Fischer, A. Gasparotto, C. Maccato, G. Sberveglieri, E. Tondello, 1D ZnO nanoassemblies by Plasma-CVD as chemical sensors for flammable and toxic gases, Sensors and
Actuators B 149, 1-7 (2010); doi: 10.1016/j.snb.2010.06.048.

[3] A. Fort, M. Mugnaini, S. Rocchi, V. Vignoli, E. Comini, G. Faglia, A. Ponzoni, Metal-oxide nanowire sensors for $\mathrm{CO}$ detection: Characterization and modeling, Sensors and Actuators B 148, 283-291 (2010); doi: 10.1016/j.snb.2010.04.034.

[4] N. Kaur, D. Zappa, M. Ferroni, N. Poli, M. Campanini, R. Negrea, E. Comini, Branch-like $\mathrm{NiO} / \mathrm{ZnO}$ heterostructures for VOC sensing, Sensors and Actuators B 262, 477-485 (2018); doi: 10.1016/j.snb.2018.02.042. 